\title{
SOBRE ALTERIDADE E O SAGRADO EM UMA ÉPOCA DE GLOBALIZAÇÃO. O "TRANS" EM "TRANSNACIONAL" É O MESMO "TRANS" DE "TRANSCENDENTE"?
}

Joel Robbins

É um traço comum a vários tipos de cristianismo, o paraíso (heaven) pensado como estando muito distante da Terra, geralmente em algum lugar no céu (sky)*. Esta é uma observação banal, tão corriqueira que tende a não ser muito mencionada nos relatos etnográficos das comunidades cristãs. Considerem-se, no entanto, as duas vinhetas etnográficas a seguir, que mostram a importância de tal idéia para cristãos conversos que vivem em partes remotas de Papua-Nova Guiné.

A primeira vem de minha própria pesquisa entre os Urapmin, grupo que vive na província do Sepik Ocidental e que se converteu em sua totalidade a uma forma carismática de cristianismo, por ocasião de um movimento de reavivamento no fim dos anos 1970. Rom é um dos mais destacados membros da comunidade urapmin e um de seus líderes políticos, uma pessoa geralmente contida e equilibrada. É também aquela mais afeita aos ocidentais e aos papuásios ocidentalizados, tendo trabalhado por um ano, durante a adolescência, na casa de um administrador de uma plantação de chá. Isto faz com que seja naturalmente escolhido para estar à frente em todos os assuntos da comunidade com pessoas de fora, como funcionários do governo ou prospectores de minérios. Paralelamente ao status de líder político, Rom é reconhecido como um cristão muito instruído, sendo um dos que concluiu um curso de uma "escola bíblica" que tem prestígio naquela região e foi iniciada por um homem de um grupo étnico vizinho. De todos os Urapmin, Rom é quem mais aproveitou

\footnotetext{
* [N.T.]: No original: "heaven is referred to as the 'place [clearing] in the sky'". Em inglês, heaven tem uma conotação religiosa, enquanto sky designa o céu em sentido atmosférico e astronômico; o termo firmamento é o equivalente português de sky, em denotação e conotação, mas é do registro culto, fazendo os nativos da tradução soarem um tanto quanto rebuscados - ao menos mais bem-falantes do que aparecem no original.
} 
as oportunidades abertas pelas mudanças culturais que se seguiram ao contato com o Ocidente - um contato que para os Urapmin só começou significativamente nos anos 1940, quando se desencadeou a colonização. Dotado de grande inteligência, Rom encara as coisas sem se perturbar, e com mínimo estardalhaço toma geralmente ótimas decisões, tanto para si quanto para a comunidade urapmin.

Tendo conhecido Rom como uma pessoa segura de si, fiquei surpreso, certo dia, ao encontrá-lo profundamente perturbado por algo que havia sabido em uma viagem a uma das aldeias situada próxima ao escritório do governo em Telefolmin, distante cerca de meio dia de caminhada, a leste. Lá encontrou um jovem que, estando em contato com a mãe falecida, que lhe enviava mensagens de algum lugar subterrâneo, estabelecera-se como uma espécie de profeta. De maneira geral, os Urapmin dão muita atenção à possibilidade de que a segunda vinda de Jesus seja iminente, e estão propensos a, no mínimo, dar ouvidos a quem quer que afirme ter conhecimento sobre o tempo em que se dará esse evento esperado com ansiedade (e também com apreensão). Imagino que foi nesse espírito que Rom visitou aquele profeta e ouviu o que ele tinha a dizer, apesar do fato de os profetas, como tais - aqueles que afirmam ter fontes regulares de revelações, por oposição àqueles que recebem do espírito santo um sonho ou uma visão não serem comuns na região nem serem objeto de muito interesse. Mas o que Rom soube do profeta o abalou mais do que qualquer outro prognóstico apocalíptico anterior, ao menos comparativamente ao que pude observar. O profeta lhe contara que sua mãe havia dito que não existe o paraíso, e que Jesus viria exatamente como na Bíblia. Depois de sua vinda, os bons cristãos teriam vidas perfeitas de harmonia e abundância, mas isso seria na Terra, exatamente nos lugares onde vivem agora. As coisas seriam bem melhores, mas não havia outro lugar aonde ir. Essa profecia perturbou fortemente Rom porque, conforme contou, ele havia aprendido que o paraíso não era na Terra - e isso era importante para ele. Que o paraíso seja na Terra, isso simplesmente não pode ser verdade, ele afirmava. Com uma atípica dificuldade de encontrar palavras para expressar-se, ele não dizia mais que isso; mas deixava bem claro que, se de fato não houvesse o paraíso, se tudo que o cristianismo pudesse prometer fosse o paraíso na Terra, ele se sentiria profundamente traído.

Na ocasião seguinte em que encontrei Rom, ele parecia recuperado do choque infligido em sua ontologia pelo profeta, e como este não chegou a se tornar uma figura importante no cenário regional (talvez porque também para outras pessoas, como para Rom, a mensagem fosse inassimilável), nunca voltamos a falar sobre isso. Rom, como era de se esperar, acabou encontrando 
uma maneira de manter seu mundo girando de um modo com o qual lhe fosse possível conviver, mas o esforço para consegui-lo, nesse caso específico, fez dele um episódio marcante de minha pesquisa de campo.

O segundo caso que eu gostaria de discutir talvez tenha tido conseqüências mais duradouras, ao menos para um dos participantes. Envolve um Ipili, do vale Porgera, na província de Enga. Desde 1990, Porgera abriga um grande empreendimento de mineração de ouro, que fez chegar às mãos das pessoas do local imensas quantidades de dinheiro, para os padrões de Papua-Nova Guiné. Mas o dinheiro não está igualmente distribuído; nem todos são ricos e, além disso, a maior parte dos Ipili ainda tem a sensação de que a área em que vive é frustrantemente remota, em termos geográficos, e que isso lhes dificulta o estabelecimento de conexões com o mundo "desenvolvido". Embora os Ipili possam parecer ricos e desenvolvidos pelo padrão de medida que os Urapmin tendem a empregar nesse tipo de juízo, ambos os grupos de fato compartilham avaliações similares quanto à posição marginal que têm em relação ao mundo mais amplo.

No fim dos anos 1990, Jerry Jacka (2005:643-644) conversava com alguns homens ipili que lhe haviam feito perguntas sobre a Estação Espacial Internacional, assunto que surgia com bastante freqüência quando as pessoas descobriam que ele vinha dos Estados Unidos. Após ouvir a descrição um tanto detalhada da estação, Semai Kakopeya, o mais velho do grupo, observou casualmente que a estação espacial "deve ficar bem perto de Jerusalém" (2005:643). Jacka, não entendendo o sentido de Jerusalém para Semai (ele se referia à "nova Jerusalém", expressão com que os cristãos às vezes se referem ao céu), respondeu que com certeza não era assim, pois Jerusalém ficava na Terra e a estação espacial, no céu. Diante da resposta, Semai rapidamente irritou-se. Disse que os pastores sempre haviam dito aos Ipili que, se fossem salvos, iriam para o paraíso, para a "Jerusalém no céu", e que se Jerusalém e a estação espacial estão ambas no céu, devem estar perto uma da outra. Em vista dessa nova informação, de que Jerusalém não está no céu, Semai declarou, com raiva, que as pessoas deviam parar de dar dinheiro para a igreja. No dia seguinte, ele contou a Jacka que estava pensando em deixar a instituição ou, ao menos, parar de fazer contribuições. "Durante todo esse tempo", ele disse, "pensei que estava dando dinheiro para garantir meu lugar em Jerusalém. Agora, descobri que estava mandando dinheiro para alguns homens brancos que vivem na Terra" (2005:643). Outro Ipili com quem Jacka discutiu a questão teve reação similar de decepção, embora aparentemente com menos raiva: "mortificado e também desencantado... [ele] comentou: 'pensei que realmente soubéssemos onde ficava o céu'" (2005:644). 
Para Rom, Semai e o jovem anônimo citado por Jacka, a idéia de que o céu pudesse ser um lugar na Terra era profundamente perturbadora. No caso de Rom, o profeta havia dito explicitamente que o mundo em que os cristãos viveriam após o retorno do Cristo seria ainda paradisíaco em comparação com aquele em que vivem agora; e Jacka não relata que tenha contado mais nada sobre Jerusalém aos homens ipili, além do fato de que ela tinha uma localização terrena. Mas estas simples informações pareceram suficientes para perturbar profundamente os cristãos em lugares para os quais a religião havia sido recentemente importada e onde sua chegada estava estreitamente ligada a processos de colonialismo e de globalização econômica e cultural. Este artigo pretende examinar por que razão a distinção entre céu e Terra é tão importante para essas pessoas e, de modo mais geral, por que razão as versões do cristianismo que enfatizam a diferença e a distância entre estes dois lugares são tão populares em locais tornados remotos pelo sistema mundial da modernidade globalizada. Por que - é o que quero indagar - a separação entre os dois reinos constitui parte tão popular das cosmologias religiosas, e o que significa a notícia do seu colapso potencial para as pessoas que sentem essa possibilidade como algo tão profundamente desestabilizador?

\section{Alteridade, transcendência e religião}

Thomas Csordas, na introdução que escreveu a um número recente de uma revista, por ele organizado, menciona "a imanência da alteridade mesma como núcleo fenomenológico da consciência religiosa e da subjetividade" e afirma que "essa alteridade é a base para a ressurgência global da religião" (Csordas 2007:266). O argumento está referido a uma obra anterior, sua grande formulação a respeito da teoria da religião, na qual desenvolve a idéia de que "o objeto da religião é a alteridade mesma" (Csordas 2004:173). No entanto, ele também vai além dessa declaração anterior e, ao menos implicitamente, oferece outra, que vincula de um lado a multiplicação radical das oportunidades de se experimentar a alteridade - tal como propiciadas às pessoas por esta época de globalização - e, de outro, o aumento vertiginoso, em vários lugares, da expressão religiosa e talvez também do compromisso religioso. É essa a linha de pensamento que quero desenvolver mais detalhadamente, ao procurar dar conta da importância de um céu que está alhures, para as pessoas na Papua-Nova Guiné e em outros lugares em que a conversão ao cristianismo ou, mais especificamente, a formas de cristianismo que enfatizam a distância entre o céu e a Terra - é um fenômeno contemporâneo. 
A explicação teórica da religião proposta por Csordas tem por objetivo traçar a "estrutura elementar" — ou, recorrendo novamente, aqui, a uma frase que aparece no seu escrito mais recente, o "núcleo fenomenológico" da alteridade que dá conta da tendência humana a produzir religiões (2004:176). Este núcleo, ele o vê na alteridade íntima da encorporação [embodiment]", tal como descrita por fenomenólogos como Merleau-Ponty, que indicam em que sentido nossos corpos são parte de nossa pessoa e também alheios a nós. Ele considera tal experiência como universal, e aquela que garante o encontro fundamental e inescapável com a alteridade que alicerça a imaginação religiosa. Mas meu interesse é um tanto menos geral e, para persegui-lo, não há necessidade de me fazer acompanhar desse argumento a favor de uma fonte elementar singular da experiência da alteridade. ${ }^{1}$ Em vez disso, quero recorrer ao insight de que a religião tem na alteridade seu objeto e, além disso, de que as diferentes religiões elaboram diferentemente a noção de alteridade - pontos em que se pode concordar com Csordas mesmo sem tomar posição quanto à questão de a alteridade assim elaborada ter ou não, em última instância, uma única fonte experiencial ou existencial (Csordas 2004:176).

Decidi enfrentar a questão do papel central da alteridade na religião porque, segundo o modo de ver dos cristãos da Papua-Nova Guiné apresentado na seção anterior, o céu nada é, se não for uma figura da alteridade e, nesse sentido, qualquer tentativa de sugerir que o céu possa ser, nesse aspecto, uma figura menos radical do que aquela que imaginavam é muito perturbadora. O caráter radical da alteridade do céu é um ponto crítico do entendimento religioso dessas pessoas e, para refletir sobre isso, vale a pena voltarmo-nos para um discurso teórico bem diferente - um discurso que, em vez de concentrar o foco no lugar que a alteridade em geral ocupa em todas as religiões, deu muita importância ao papel da alteridade radical em algumas delas (inclusive o cristianismo). Penso no discurso teórico geralmente conhecido como hipótese da época axial.

Originalmente proposta por Jaspers (1953), e elaborada por Eisenstadt (1982) naquela que é, para nossos propósitos, sua forma mais influente, a hipótese da época axial tem como asserção principal a ocorrência, durante o período que vai aproximadamente do oitavo ao terceiro séculos antes da era cristã, de um conjunto de revoluções similares no plano das idéias e no

\footnotetext{
* [N.E.] Utilizamos o neologismo "encorporação" tal como proposto por Viveiros de Castro (1996:138): "Traduzo a forma inglesa to embody e seus derivados, que hoje gozam de uma fenomenal popularidade no jargão antropológico (ver Turner 1994), pelo neologismo 'encorporar', visto que nem 'encarnar' nem 'incorporar' são realmente adequados."
} 
da fundamentação institucional destas: revoluções observadas em várias culturas eurásicas, aí incluídas as do "Israel antigo, Grécia antiga... Irã zoroastrista, antiga China Imperial, e nas civilizações hindu e budista". Cristianismo e islamismo, embora posteriores, basearam-se em idéias que têm origem, reconhecivelmente, naquela época (Eisenstadt 1982:294). As revoluções da época axial distinguiram-se por levar à "emergência, conceitualização e institucionalização de uma tensão básica entre a ordem transcendente e a mundana" (1982:294). Esta foi a tensão que, sob uma ou outra forma, todas as civilizações da época axial partilharam. Em todas elas, as pessoas percebiam "uma nítida disjunção entre o mundano e o transmundano" e enfatizavam "a existência de uma ordem superior transcendente ou metafísica, que está mais além de toda realidade deste ou de qualquer outro mundo" (1982:296). A idéia de céu, compartilhada pelos dois papuásios do início do artigo, pertence a um mundo marcado por este tipo de separação entre domínios, separação que é radical e também hierárquica, sendo o transcendente mais valorizado.

Para que a hipótese da época axial tenha interesse, deve-se aceitar que este tipo de divisão não tinha lugar nas culturas pré-axiais. Em termos concordantes com a sugestão de Csordas, de que a alteridade é o objeto de todas as religiões, Eisenstadt (1982:296) reconhece que "a ordem transmundana tem sido percebida, em todas as sociedades humanas, como algo que de algum modo é diferente, geralmente superior ou mais forte que a ordem mundana". Mas ele prossegue e afirma que "nas civilizações 'pagãs' da época pré-axial, esse mundo superior foi simbolicamente estruturado segundo princípios muito similares aos do domínio inferior ou mundano" (1982:296). Além disso, nestas civilizações, "a concepção de uma ordem moral autônoma e distinta, que é qualitativamente diferente deste mundo e também do 'outro mundo', desenvolveu-se em grau mínimo" (1982:296). O tipo de dicotomização em que Eisenstadt está empenhado aqui não é popular na antropologia atualmente, especialmente quando posta a serviço de argumentos do tipo nós/eles (uma das direções a que a hipótese da época axial pode levar). No entanto, não é menos verdade que não seja difícil, para antropólogos que trabalham em lugares como a Papua Nova Guiné, reconhecer alguma força na alegação de que as religiões tradicionais não estavam estruturadas em torno de uma distinção radical entre o transcendente e o mundano. Nas religiões deste tipo, os deuses são geralmente ancestrais, parentes em última instância e, mesmo quando isto não se verifica, considera-se geralmente que respondem a várias situações de maneira semelhante aos homens e mulheres do presente. São mundos de um tipo em que - conforme de Coppet e Iteanu (1995) sugeriram em relação às culturas da Oceania — cosmos e sociedade 
são uma coisa só. São lugares em que o foco na "alteridade íntima", a que se refere Csordas, capta o teor da vida religiosa melhor que aquele tipo de postura que vem da ênfase no encontro com o "completamente outro", fomentado pelas religiões axiais. Há muito mais a dizer no sentido de especificar de que modo, em muitas culturas, as ordens transcendente e mundana não estão radicalmente distinguidas. Para os propósitos deste texto, no entanto, eu não quis mais do que tentar esboçar o modelo básico das religiões nãoaxiais segundo Eisenstadt, para deixar claras a natureza e a profundidade das mudanças que a época axial teria introduzido.

Para Eisenstadt e outros teóricos da época axial, a abertura de um hiato entre os domínios mundano e transcendente suscita a criação de uma elite intelectual determinada (incluindo personagens como profetas e revolucionários), cujo propósito seria o de esclarecer a natureza do transcendente e que não raro acaba por liderar movimentos que encorajam as pessoas a tentar realizar os fins transcendentes dentro do domínio mundano. Por uma série de argumentos complexos, a reflexividade social e o impulso revolucionário dos intelectuais axiais são tidos como cruciais para a produção da modernidade (ver Eisenstadt 1999 para o argumento completo e uma ampla e útil bibliografia). As modernidades diferem no modo com que nelas atuou o impulso axial de reconstituição da sociedade com base em visões transcendentes, e por isso Eisenstadt (2000) é, já há algum tempo, um proponente da noção de múltiplas modernidades. Na sua versão, no entanto, a tensão entre os domínios claramente distintos e hierarquicamente dispostos do mundano e do transcendente foi uma força impulsionadora das dinâmicas de desenvolvimento de quase todas as sociedades que chamaríamos modernas (a exceção é o Japão contemporâneo, a respeito do qual veja-se Eisenstadt 1996).

Feito este breve resumo que acabo de apresentar, talvez não surpreenda que a hipótese da época axial praticamente não tenha sido aproveitada na antropologia. Como já foi observado acima, o binarismo do nós-axiaismodernizantes versus eles-pré-axiais-tradicionais exemplifica um estilo de operação distinguidora que não encontra ressonância alguma na disciplina atual. Além disso, como Wagner (2005:89) proveitosamente indicou, a discussão sobre a época axial oscila desconfortavelmente entre "dois gêneros de investigação bem diferentes... a saber: a sociologia histórica e a filosofia da história". Ela é marcada tanto pela construção de algumas distinções típicoideais úteis entre espécies de formações culturais, quanto por temerárias discussões sobre a relevância de transformações consideradas fundamentais na consciência humana e na capacidade de agência, e seus efeitos sobre larguíssimos feixes temporais. O próprio Eisenstadt (2005:532) observou recentemente que os fatores "tipológicos" precisam ser distinguidos dos 
"cronológicos" no debate. Seguindo aqui sua indicação e a de Wagner, podemos sugerir que os antropólogos são extremamente alérgicos à filosofia da história e à tendência a produzir análises que façam alegações grandiosas a respeito de vastos períodos de tempo.

Se é este o caso, poderemos deixar de lado os aspectos da hipótese da época axial e ainda assim selecionar e pôr à prova as afirmações tipológicas e sociológico-históricas desenvolvidas pela literatura da era axial. É precisamente o que sugiro fazermos.

Se adotamos essa abordagem, a afirmação tipológica crucial a ser escolhida é aquela segundo a qual existe uma diferença entre as culturas que distinguem o transcendente e o mundano de modo radical e hierarquizado e aquelas que não separam tão profundamente estes dois domínios. Se observarmos a lista canônica das culturas axiais - que inclui as que geraram judaísmo, hinduísmo, budismo, cristianismo e islamismo - também podemos notar que as religiões geralmente tidas como aquelas que se mundializaram são as mesmas em que a ruptura axial teve um papel-chave. O que é singular, nelas, não é que ponham o foco na alteridade, mas o fato de a tratarem de um modo especial: como algo absoluto, ou ao menos bem marcado, e que tem mais valor do que o que é familiar. Podem-se apresentar várias respostas para a razão por que religiões com essas características tenderiam a deslocar-se tão melhor do que as outras - e uma delas seria o modelo de Eisenstadt, das culturas axiais como produtoras de uma elite intelectual determinada a difundir sua visão, num esforço para refazer o mundo em termos transcendentes. Aqui, porém, quero encarar a questão de outro ângulo. Ou seja, ao invés de perguntar como os portadores das religiões axiais quiseram difundi-las, indagar por que aqueles a quem elas foram transmitidas quiseram adotá-las. E para que a análise seja exeqüível, restringirei minhas considerações à difusão do cristianismo pentecostal e carismático durante a época contemporânea de globalização.

\section{Transcendência e a globalização do cristianismo pentecostal e carismático}

Pode-se dizer que as formas carismática e pentecostal de cristianismo vêm sendo, nas últimas décadas, um dos casos mais bem-sucedidos de globalização cultural. Tipos de cristianismo focados na acessibilidade dos dons do Espírito Santo a todos os crentes contemporâneos, elas se espalharam rapidamente em todo o mundo desde o nascimento do pentecostalismo, nos primeiros anos do século XX. As últimas três décadas, aproximadamente, se 
afiguram um período de crescimento especialmente rápido na Ásia, América Latina, África e Oceania; estimativas recentes sugerem que o cristianismo pentecostal e o carismático possuem, no presente, cerca de 523 milhões de adeptos, dois terços dos quais vivem fora do Ocidente, local de origem destas religiões (Barrett e Johnson 2002:284).

Junto com tais índices quantitativos do sucesso globalizado dessas religiões, deve-se notar também em que medida elas conseguiram reproduzir seus princípios básicos na maioria das culturas em que foram introduzidas. Cristianismo pentecostal e cristianismo carismático, como paradigmas do que Appadurai (1996) chama de "formas culturais duras" [hard cultural for$\mathrm{ms}$ ] - aquelas que as pessoas tendem a tomar em conjunto, sem refazê-las inteiramente em bases locais - deram mostras de notável capacidade de preservação de sua forma original, à medida que viajavam pelo globo (Robbins 2004a). Assim, seja em termos quantitativos ou qualitativos, eles devem figurar como parte principal no ressurgimento religioso global em curso.

Com relação ao argumento que tento desenvolver aqui, o mais notável nos cristianismos pentecostal e carismático é o modo como lidam com a separação entre o transcendente e o mundano. Quanto a isso, duas características chamam a atenção. Em primeiro lugar, a forte ênfase nesta separação. Ambos tendem a demonizar a Terra, considerando-a um lugar ocupado pelo mal e pela tentação, e igualmente a vida que aí levam as pessoas, quase sempre entregues ao pecado. O sagrado local, modelo falso de transcendência, também é tratado como matéria terrena e sujeito ao vigoroso ataque dos crentes instados a participarem da "guerra espiritual" contra os espíritos tradicionais (DeBernardi 1999; Jorgensen 2005). Além disso, os modos culturais e locais da vida na Terra são igualmente definidos como maus, sendo os adeptos compelidos a "quebrarem completamente com o passado", conforme relata Meyer (1998) a respeito de Gana. Em contraposição à forma carismática e pentecostal de tratar a Terra como espaço do mal, tem-se a ênfase de ambas as religiões no céu como um paraíso perfeito, um lugar em que serão resolvidos todos os problemas que afligem as pessoas em suas vidas terrenas, e onde cada um de nós poderá viver sem pecado. A mudança da Terra para o céu será descontínua, programada para acontecer quando Jesus retornar. Não faz sentido, nessas religiões, que os crentes procurem criar, na Terra, o céu ou um fac-símile deste último. Nos cristianismos pentecostal e carismático, a separação entre o transcendente e o mundano é, portanto, tão extrema quanto nas demais formas de cristianismo ou em qualquer outra religião mundial.

A segunda característica notável do modo pentecostal e carismático de lidar com a distância entre o céu e a Terra reside na sugestão de que esta 
disjunção é mediada regularmente pelo Espírito Santo, que pode preencher as pessoas na Terra do poder celestial de Deus, para permitir-lhes, entre outras coisas, falar línguas, curar, profetizar, levar uma vida moral e trazer outros para a fé. O Espírito Santo - quero enfatizar o que acabei de afirmar acima - não dá às pessoas a capacidade de criar o céu na Terra, ele apenas as ajuda a lidar com alguns dos problemas deste mundo e a cultivar a forte crença e a retidão de comportamento, dos quais elas precisarão dar mostras se quiserem estar entre os salvos quando vier o milênio. A diferença entre céu e Terra permanece absoluta, mas a mediação do Espírito consolida, sim, uma conexão entre os dois domínios, que mantém a promessa do céu para aqueles que crêem, e lhes fornece o poder de que precisam para agir tendo em vista o direito a passar de um reino ao outro quando Jesus retornar.

A ênfase colocada nas mediações que permitem às pessoas experimentarem parte do poder do céu na Terra distingue estas formas de tantos outros tipos de cristianismo. Quero sugerir aqui que tal distintividade no modo de lidarem com o tema axial da diferença entre transcendente e mundano, combinada com a tendência a não obstante enfatizarem a enormidade da distância entre os dois domínios, fez delas a poderosa força globalizadora que se observa, hoje.

Talvez seja melhor começar por um ponto óbvio que, no entanto, ainda não vi mencionarem, relativo à prodigiosa semelhança entre a estrutura da cosmologia axial pentecostal e carismática e os mundos sociais de tantos povos que se encontram na periferia da economia global de mercado e que se converteram a essas religiões nas últimas décadas. Para muitos deles, em particular aqueles que não saíram de seu lugar original, ou que não foram mais longe do que a ocupação urbana mais próxima - no caso daqueles que provêm de áreas mais rurais — o significado da globalização tem sido o de passarem a ver a si próprios como não mais vivendo em um lugar central, ou dotado de poder. Entre eles, há uma profunda sensação de que o verdadeiro poder, o sucesso econômico e a saúde estão alhures. As pessoas, onde quer que faça sentido falar em globalização, vieram a reconhecer alguma versão de uma hierarquia global de lugares e, para aquelas que constituem o foco deste artigo, aqueles mais valorizados - em que o trabalho é abundante, em que alimentos, abrigo e remédios são fáceis de adquirir — são longínquos e diferentes de casa, em grau máximo. E assim como seus mapas sociais reconhecem grandes distâncias entre os lugares e conferem valor superior àqueles mais distantes de onde vivem, assim também os mapas cosmológicos pentecostal e carismático, adotados por essas pessoas, desvalorizam maximamente os lugares de sua vida terrena e lhes dizem que aquele em que elas realmente querem estar é o céu, que em nada se assemelha ao lugar onde vivem. 
Para dizê-lo de modo mais simples, a disjunção axial existente na cosmologia pentecostal e carismática entre o domínio mundano e aquele, mais valorizado, do transcendente, espelha a disjunção que a globalização produz entre os lugares locais e aqueles, mais valorizados, centrais ou "globais" que, em conjunto, constituem a paisagem social. Mas as homologias entre os dois modelos de espaço vão além. Para as pessoas da periferia da economia do mercado global, ao menos uma parte daquilo que querem do centro - coisas como dinheiro, mercadorias e conhecimento - chega até elas, embora não raro de modo não inteiramente consumado. Na periferia tal como ela é vista pelas pessoas - pode-se às vezes ter um emprego, mas não um que seja estável ou que pague o bastante para sustentar o modo de vida que se deseja ter; pode-se ocasionalmente comprar roupas bonitas, mas não da última moda etc. Além do mais, as idéias e imagens que vêm do centro estão regularmente disponíveis e muito fazem para orientar o desejo na direção da vida que se vive nos lugares centrais. No entanto, esses fragmentos do moderno global que as pessoas podem chegar a possuir nunca são suficientes para que elas possam tornar central o espaço de suas vidas. Similarmente, nos cristianismos pentecostal e carismático, o Espírito Santo realiza uma parte do céu na Terra. E, no entanto, mesmo que se possa por vezes apelar para o socorro do poder de Deus na resolução de problemas terrenos, não se pode usá-lo para transformar a Terra no céu. Em ambos os modelos, as pessoas de lugares periféricos/mundanos têm algum acesso aos centrais/transcendentes, mas não podem, em nenhum deles, do modo como as coisas estão aí dispostas, reduzi-los a um só.

O que estou propondo não é que para as pessoas da periferia essas homologias tornem-se identidades - que o céu pareça uma cidade global ou que haja pouca diferença entre o Espírito Santo e um bolso repleto de dinheiro. Pela minha experiência na Papua-Nova Guiné, e com base na literatura sobre cristianismos pentecostal e carismático globais em outras regiões, é raro ver essa combinação categórica dos dois modelos (ver, abaixo, minha discussão das idéias de céu entre os Urapmin). O que quero afirmar, em lugar disso, é que para as pessoas das periferias, a cosmologia pentecostal e carismática é boa para pensar, por espelhar estruturalmente o modelo global com o qual elas cada vez mais passam a interpretar suas vidas. Ela fornece um idioma com o qual se pode discutir de modo significativo sobre o que é viver longe dos centros últimos do poder, do sentido e do bem-estar no mundo. Mas além de ser, digamos assim, boa para pensar, essa cosmologia também é boa para viver, e de um modo que com freqüência não é como o do mapa social da globalização. É boa para viver porque sugere às pessoas que se vêem como periféricas no mapa social, maneiras de conduzirem 
vidas que ainda tenham, em última instância, valor, porque empreendidas em preparação para o céu. Além disso, as maneiras de viver promovidas por tal cosmologia são quase sempre daquele tipo a que as pessoas podem ter acesso empregando apenas os recursos de que dispõem (Robbins 2004a). Diferentemente da globalização - que tão freqüentemente exige das pessoas que querem vir para o centro transformações através de experiências de educação e de trabalho que elas não têm condições de obter os cristianismos pentecostal e carismático oferecem planos exeqüíveis para que as pessoas possam viver em busca do seu objetivo de alcançar o céu. A cosmologia lhes fornece meios de pensar em suas práticas de construção da vida como voltadas para algo de grande valor, ainda que não sejam capazes de dispor, para tal tarefa, dos recursos do centro. É para este processo de construção da vida que pretendo voltar-me na seção a seguir, e conferir-lhe alguma especificidade ao observar de que modo ele se desenvolve no caso dos Urapmin.

\section{Vivendo para o céu}

Os Urapmin, cuja comunidade inteira, como anteriormente mencionado, converteu-se ao cristianismo carismático no fim dos anos 1970, vêem-se como socialmente marginalizados em relação ao mundo da modernidade global, nos termos delineados acima. Eles gostam de referir-se a si próprios como "a última Nova Guiné", significando que tudo o que é moderno, do dinheiro à medicina e ao cristianismo, só chega até eles quando já se espalhou por todos os outros lugares (cf. Jacka 2005:649). Este sentimento de estar na periferia do sistema global é profundamente perturbador para eles, ainda mais por se considerarem anteriormente centrais dentro do mundo regional que constituía o quadro de referência mais importante, antes do contato (Robbins 2004b:84-121). Há dois modos básicos de imaginar como resolver sua atual marginalidade: um é o advento do desenvolvimento, que eles costumam figurar na forma da construção de uma grande mina em suas terras, capaz de rivalizar com a imensa Ok Tedi, construída no início dos anos 1980 nas terras dos seus parceiros de comércio, a cerca de quatro dias de caminhada, na direção norte. A outra é a segunda vinda de Jesus que, acreditam, fará com que os Urapmin "crentes fervorosos" sejam levados a um céu em que ninguém é marginalizado. Do ponto de vista de um analista, a diferença clara entre estas duas maneiras de responder à marginalidade social centra-se no fato de os Urapmin poderem operar para sua própria salvação, sem ajuda externa (exceto a do Espírito Santo, cujo auxílio está 
largamente disponível), mas não terem como promover o desenvolvimento (cf. Knauft 2002, a respeito da passividade que os outros tipos de cristianismo, não focados nos dons do Espírito Santo, podem fomentar). Os Urapmin não falam desta maneira a respeito da diferença entre os dois modos de responderem à marginalização, mas com certeza valorizam a salvação mais do que o desenvolvimento, e o exame das razões para fazê-lo nos ajudará a entender de que modo o caráter axial do seu cristianismo tem sido crucial no enfrentamento da marginalização que a globalização lhes legou.

Para entender por que os Urapmin valorizam a salvação acima do desenvolvimento, é preciso antes de mais nada notar que o cristianismo carismático que adotam está construído em torno de uma separação muito marcada entre os domínios transcendente e mundano. O céu é designado como o "lugar [clareira] no firmamento" (abiil tigin) ${ }^{2}$ e tido como fisicamente distante da Terra. As pessoas muitas vezes sonham que vêem indivíduos ou grupos serem conduzidos ao céu por Jesus, cada vez mais longe, até desaparecerem nas nuvens. O céu também é um lugar em que as pessoas não terão pecados nem os desejos que na Terra as conduzem ao pecado. Os Urapmin especulam que possa mesmo ser verdade que as pessoas não tenham corpo nem gênero, no céu. E ainda que não seja assim, no mínimo não haverá distinção entre pessoas de pele preta e branca (é principalmente nos termos desta distinção racial que os Urapmin falam da oposição entre local/tradicional e global/moderno - ver Robbins 2004b). Tampouco haverá fome, e as pessoas poderão viajar à vontade e rapidamente para onde quiserem (cf. Jacka 2005:648-9 para idéias similares dos Ipili a respeito do céu; ver também Jebens 2005, para idéias comparáveis em outra sociedade da Papua-Nova Guiné). Este conjunto de características não é algo que os Urapmin imaginem que as cidades modernas possuam, embora pensem que elas estejam mais próximas desta condição do que suas próprias aldeias. Trata-se, antes, do retrato de um lugar em que as coisas difíceis da vida, especialmente as dificuldades decorrentes da condição marginal no sistema global, estão invertidas: onde há carência e desejos que levam ao pecado, haverá saciedade; onde há estasi, haverá movimento; onde há fome, haverá abundância; onde há, do modo mais geral, marginalização, haverá centralidade. Como em todas as religiões axiais, o cristianismo urapmin está construído sobre a idéia de que a vida no mundo transcendente será melhor do que a vida na Terra.

Ao longo da descrição do céu como um lugar melhor do que a Terra, já fui obrigado a indicar de que modo os Urapmin vêem a vida no que eles chamam "este chão" (towal diim). Ela é cheia de desejo e pecado, ira, discórdia e adversidade. É também uma vida de marginalidade. Como já tive 
ocasião de discutir em detalhes (Robbins 2004b). o modo como os Urapmin experenciam nesses termos a vida terrena, não acrescentarei, aqui, mais informações a respeito. Bastará notar que, sendo a existência terrena uma inversão da vida no céu, ela também é diferente em grau máximo daquela vida. A distância física entre o céu e a Terra, portanto, representa, em sua enormidade, a extensão da diferença entre as formas como a vida é vivida em cada um destes lugares.

Os Urapmin, reconhecendo a separação extrema dos domínios mundano e transcendente, também tornaram-se muito eficientes na crítica à vida terrena do ponto de vista do transcendente - outro traço-chave do modelo axial. A luta que anima a vida dos Urapmin e lhes dá uma direção é aquela na qual, contra todas as atrações e compulsões terrenas, as pessoas procuram viver moralmente, em conformidade com os padrões do céu. Cultos na igreja (realizados no mínimo três vezes por semana, mas não raro com maior freqüência), encontros de aldeias e debates particulares estão repletos de exortações morais (weng titil, literalmente "fala forte", e weng kem, literalmente "fala clara") concentradas na propensão das pessoas a seguirem pelos caminhos terrenos e daí seu fracasso em corresponder aos ditames do céu. Estas admoestações, parte tão substancial daquilo que se diz no dia-adia, fazem com que o transcendente diga respeito ao mundano, na medida em que reforçam a realidade do hiato crescente entre ambos. A esperança animadora daqueles que proferem tais exortações é a de que bastará que se consiga estar à altura do modelo moral celeste nelas expresso para poder deixar para sempre a Terra, quando Jesus retornar.

A esperança de que se possa cumprir aquilo que é exigido nas exortações é encorajada pelo fato de o Espírito Santo ajudar aqueles que crêem a viver segundo as exigências da moralidade transcendente. Os que têm o Espírito em seus corações (aget tem; para os Urapmin, o coração é a sede de todo pensamento, sentimento e motivação) são aqueles capazes de se aproximar da perfeição moral exigida pelo céu, mesmo quando ainda vivem na Terra. Grande parte da vida ritual dos Urapmin, que vai da prece particular a danças grupais de possessão — um elemento onipresente na rotina diária — tem por objetivo pedir ao Espírito ajuda neste esforço. É assim que a mediação, pelo Espírito, entre o transcendente e o mundano torna a convivência com o hiato um projeto dotado de sentido. Ainda que o céu não seja alcançável antes da vinda do milênio, há bastante de seu poder disponível aqui e agora, na Terra, para tornar a vida um projeto realizável.

Não se pode dizer o mesmo do projeto de se viver vidas "desenvolvidas". Os Urapmin estão constantemente e dolorosamente cônscios de que não têm parcela suficiente do "poder" (powa) ou do "conhecimento" ( $\underline{\text { save }}$ ) do 
centro ocidental para construir vidas que estejam efetivamente voltadas ao objetivo de torná-los desenvolvidos. As mediações que se oferecem entre eles e o centro simplesmente não fornecem as ferramentas de que necessitariam para realizar tal tarefa. A única esperança de que isso possa mudar, a qual se apegam, vem da possibilidade, já mencionada, do desenvolvimento da mineração - esperança que recebe algum incentivo concreto com a ocasional passagem, entre os Urapmin, de equipes de prospecção de empresas multinacionais. Embora elas tenham encontrado ouro em suas terras, ainda não há certeza de que ele exista em quantidade ou concentração suficientes para tornar real essa possibilidade, numa região em que há imensos obstáculos infra-estruturais à atividade mineradora. No entanto, se considerarmos que as equipes de prospecção, no mapa global, são mediadoras de forma análoga àquela com que o Espírito Santo serve de mediador no mapa cosmológico, talvez possamos entender por que mesmo a aparição relativamente rara daquelas equipes acende intensamente sua imaginação. Mas mesmo enquanto continuam a colocar sementes de esperança na terra que as equipes de prospecção escavam e removem, eles também trabalham duro em suas falas pública e privada, para manter o desejo de desenvolvimento no seu devido lugar - um lugar com certeza subordinado ao anseio pelo céu. Conforme eles regularmente lembram a si próprios, a mineração e o desenvolvimento são apenas "coisas terrenas" (towal diim mafak mafak, samting bilong graun). Esta é a frase urapmin que melhor denota a força que a palavra "mundano" tem no pensamento da época axial: refere-se não só à proveniência terrena das coisas que descreve, mas também à sua importância secundária. O emprego da frase no discurso público e no privado sempre sinaliza uma exigência de que as pessoas não invistam demais nas coisas terrenas e que, em vez disso, voltem seus pensamentos para o céu. Quando a frase é aplicada à mineração e ao desenvolvimento, serve como um lembrete, carregado de conotações, de que o transcendente é mais importante do que o moderno global, e que as pessoas não deveriam enganar-se quanto a qual deles há de ter prioridade em suas vidas.

Podemos ficar tentados a ver, na alegação de que a mineração é terrena, algo como as "uvas estavam verdes". É bem verdade que dela se valem a cada vez que enfrentam nova decepção causada por mais uma visita de uma equipe de prospecção, sem resultados; mas recorrem a ela com muito mais freqüência, motivo pelo qual estou inclinado a analisá-la de outra maneira. Eu sugeriria que os esforços para estabilizar uma relação hierárquica clara entre salvação e desenvolvimento é o modo que têm de reconhecer que a primeira depende deles, ao passo que o segundo não está em suas mãos. É sua maneira de afirmar que, a despeito de sua recém-descoberta 
marginalidade no mapa global, ainda detêm o controle sobre seus destinos (cf. Tuzin 1997). Seu cristianismo carismático torna possível este sentido de controle, ao permitir que contraponham o domínio transcendente, para o qual podem encaminhar-se com recursos próprios, a um moderno global que não está acessível. O mesmo movimento é feito pelos cristãos pentecostais e carismáticos em áreas periféricas de todo o mundo, e isso é possível graças ao modo com que constroem a alteridade transcendente - eis uma razão crucial para terem se difundido com tanto êxito ao longo da atual era de globalização.

\section{Conclusão}

Este artigo iniciou com o caso de dois homens da Papua-Nova Guiné que se viram abalados ao ouvir relatos de que o céu da religião poderia não estar localizado no firmamento. A sugestão de que o céu poderia não ser distante da Terra provocou neles forte aflição, que interpretei como indicadora da importância da noção de alteridade absoluta para suas vidas religiosas. Ainda que toda religião trate de temas relativos à alteridade, nem todas apresentam tal apreço pelo tipo de alteridade radical em que investem as versões de cristianismo adotadas por Rom e por Semai. Para compreender a natureza deste tipo de religião, recorri aos teóricos da época axial que desenvolveram úteis e sofisticadas considerações tipológicas a respeito das religiões que enfatizam uma forte relação de alteridade entre o transcendente e o mundano. Colocando uma versão da cosmologia axial em correspondência com o tipo de mapa terreno de uma hierarquia mundial de lugares - que a globalização fez chegar até aqueles que vivem nas suas margens - procurei também explicar por que razão, para Rom e Semai, a alteridade deve ter um lugar já que o céu tem de estar em outro lugar. Jacka argumenta que para os Ipili é importante que o céu seja um lugar, devido ao papel que os lugares tradicionalmente desempenham, de "confirmar e historicizar experiências pessoais e coletivas" (2005:644, ver também 649). Não quero negar que algo assim ocorra também no caso dos Urapmin. Mas acrescentaria que o céu, para estes últimos e para os Ipili, também tem de ser um lugar porque, do contrário, não poderia fornecer-lhes os termos com que dar conta daquilo que vêem como sua marginalidade - de base geográfica - em relação ao sistema global. Quando a globalização torna tão grande número de pessoas descentradas, afastadas do centro em suas próprias vidas, produz um profundo reservatório de alteridade a ser experimentada - a sensação de que os verdadeiros poderes do mundo vêm de outro lugar e são diferentes 
daqueles antes conhecidos. E as religiões axiais buscam nesse reservatório aquilo que fundamenta sua própria expansão global.

Mas e a questão que aparece no título que dei ao artigo? Embora tenha indicado pistas para a resposta, tenho ainda de dizer se de fato o "trans" em "transnacional" é o mesmo "trans" de "transcendente". Em meu título, ressoa o do influente e pioneiro ensaio de Appiah (1991): "Is the Post- in Postmodern the Post- in Postcolonial?" A resposta que ele deu à pergunta do seu título foi um sim qualificado, na medida em que, para as elites africanas e euro-americanas, o "pós" em ambos os casos significa a rejeição de narrativas legitimadoras anteriores: a do domínio progressivo da razão, no caso pós-moderno, e a das ordens colonial/pós-colonial como incorporações dessa razão, no caso da narrativa pós-colonial. Na qualidade de invocações à rejeição do que veio antes, ambos os discursos "pós" sempre apontaram, entre outras coisas, para a necessidade de reconstrução social em um mundo no qual as certezas antigas já não vigoram. Retrospectivamente, não é difícil interpretar a ascensão de ambos os discursos a uma posição de destaque, vendo aí uma primeira resposta das elites aos efeitos perturbadores da globalização neoliberal sobre as certezas do pensamento ocidental (questão que aflora no artigo de Appiah, em sua discussão sobre a mercadorização e a ampliação da influência do mercado). Gostaria de sugerir que, no mundo contemporâneo, as religiões axiais levam semelhante tendência à rejeição e à renovação perante a globalização para além dos enclaves da alta cultura, tão bem inquiridos por Appiah.

Neste artigo, argumentei que a rápida difusão global do cristianismo pentecostal nas décadas recentes confirma a veracidade dessa afirmação e examinei o papel que ele vem desempenhando em muitos lugares: ajuda as pessoas a responderem aos encontros transnacionalmente produzidos com modos de vida diferentes e mais privilegiados, permitindo a elas imaginar uma vantagem transcendental a partir da qual possam reconstruir suas próprias vidas. A conjunção de uma crescente conexão transnacional com um crescimento rápido e vertiginoso da adesão a uma religião axial, enfatizadora da distintividade radical do domínio transcendente, leva-me a dar, como Appiah, uma resposta afirmativa à minha interrogação-título. Tanto no transnacionalismo como na transcendência, o "trans" sinaliza o desafio das alteridades distantes, ou que já foram distantes, ao sentido que as pessoas têm da própria centralidade. O reconhecimento de um mundo de pessoas e coisas que se originam além das fronteiras do lugar em que se vive, e que viajam transnacionalmente, de um modo que não está aberto às pessoas e coisas locais, traz forçosamente uma perda de confiança na centralidade do lugar que se ocupa, assim como o faz a idéia de um céu que é mais perfeito do que qualquer lugar terreno. 
Transnacionalismo e transcendência, conforme aqui discutidos, são como o pós-modernismo e o pós-colonialismo - discursos que clamam por uma rejeição das coisas do passado e uma valorização de coisas por vir. Mas há também uma diferença importante. No pós-modernismo e no pós-colonialismo, o que se rejeita é antes de tudo ideologias passadas, ao passo que o pensamento transnacionalista e transcendente rejeita principalmente os lugares em que vivem aqueles que o adotam. Esses lugares são, é claro, metonímias de modos de vida e ideologias que também devem ser superados. Nos casos aqui examinados, no entanto, o lugar é uma parte irredutível do problema. Visto das margens, na era da globalização, o céu na Terra não é absolutamente o céu.

Recebido em 19 de outubro de 2007

Aprovado em 30 de outubro de 2007

Tradução de Amir Geiger

Joel Robbins é professor do Departamento de Antropologia na Universidade da Califórnia, San Diego. E-mail: jrobbins@weber.ucsd.edu.

\section{Notas}

${ }^{1}$ Embora me pareça bem difícil negar a explicação de Csordas para o modo com que a encorporação produz experiências de alteridade, não estou tão convencido quanto à sua rejeição da afirmação de Durkheim (1995), de que os seres humanos também, inevitavelmente, experimentam a sociedade como algo ao mesmo tempo íntimo e alheio a eles. Csordas (2004:176) argumenta que Durkheim erradamente tomou uma "instância específica" da alteridade "pelo caso geral — a alteridade do social pela condição existencial geral da alteridade". Mas os seres humanos são tão inescapavelmente socializados quanto são encorporados, e me parece difícil não ver ambas as condições como igualmente primordiais na experiência humana. Estou portanto inclinado a afirmar que há pelo menos duas estruturas elementares da alteridade, que dão forma à condição humana e alimentam o desenvolvimento da religião. Esse plano de argumentação não é aquele que sigo no restante do presente artigo, mas seria interessante cogitar a fundo sobre os diferentes modos com que as fontes sociais e as fontes encorporadas da alteridade contribuem para a distinção experiencial entre "a alteridade íntima do self" e "a alteridade impositiva do completamente outro" — distinção importante para o argumento de Csordas (2004:174) e à qual terei ocasião de me referir, adiante, no texto. 
${ }^{2}$ As palavras na língua urap estão em itálico, enquanto aquelas em Tok pisin, a língua franca da Papua Nova Guiné e a mais importante no cristianismo urapmin, estão sublinhadas.

\section{Referências bibliográficas}

APPADURAI, Arjun. 1996. Modernity at large: cultural dimensions of globalization. Minneapolis: University of Minnesota Press.

APPIAH, Kwame Anthony. 1991. "Is the post- in postmodernism the postin postcolonial?". Critical Inquiry, 17(2):336-357.

BARRETT, D. B. \& JOHNSON, T. M. 2002. "Global statistics". In: S. M. Burgess and E. M. van der Maas (orgs.), The new international dictionary of pentecostal and charismatic movements. Grand Rapids, MI: Zondervan. pp. 283-302.

CSORDAS, Thomas J. 2004. "Asymptote of the ineffable: embodiment, alterity, and the theory of religion". Current Anthropology, 45(2):163-185. . 2007. "Introduction: modalities of transnational transcendence". Anthropological Theory, 7(3):259-272.

DE COPPET, Daniel \& ITEANU, Andre. 1995. "Introduction". In: D. de Coppet \& A. Iteanu (orgs.), Cosmos and society in Oceania. Oxford: Berg. pp. 1-19.

DEBERNARDI, Jean. 1999. "Spiritual warfare and territorial spirits: the globalization and localisation of a 'practical theology'". Religious Studies and Theology, 18(2):6696.

DURKHEIM, Emile. 1995. The elementary forms of the religious life. Tradução de K. E. Fields. New York: Free Press.
EISENSTADT, S. N. 1982. "The axial age: the emergence of transcendental visions and the rise of the clerics". Archives Europeennes de Sociologie, 23(2):294-314.

. 1996. Japanese civilization: a comparative view. Chicago: University of Chicago Press. . 1999. Fundamentalism, sectarianism, and revolution: the jacobin dimension of modernity. Cambridge: Cambridge University Press. . 2000. "Multiple modernities". Daedalus, 129(1):1-29. .2005. "Axial civilizations and the axial age reconsidered". In: J. P. Arnason, S. N. Eisenstadt and B. Wittrock (orgs.), Axial civilizations and world history. Leiden: Brill. pp. 531-564.

JACKA, Jerry K. 2005. “Emplacement and millennial expectations in an era of development and globalization: heaven and the appeal of christianity for the Ipili". American Anthropologist, 107(4):643-653.

JASPERS, Karl. 1953. The origin and goal of history. Tradução de M. Bullock. New Haven: Yale University Press.

JEBENS, Holger. 2005. Pathways to heaven: contesting mainline and fundamentalist christianity in Papua New Guinea. New York: Berghahn.

JORGENSEN, Dan. 2005. "Third wave evangelism and the politics of the global in Papua New Guinea: spiritual warfare and the recreation 
of place in Telefolmin". Oceania, 75(4):444-461.

KNAUFT, Bruce M.. 2002. Exchanging the past: a rainforest world of before and after. Chicago: University of Chicago Press.

MEYER, Birgit. 1998. "'Make a complete break with the past': memory and postcolonial modernity in ghanaian pentecostal discourse". In: R. Werbner (org.), Memory and the postcolony: african anthropology and the critique of power. London: Zed Books. pp. 182-208.

ROBBINS, Joel. 2004a. "The globalization of pentecostal and charismatic christianity". Annual Review of Anthropology, 33:117-143. . 2004b. Becoming sinners: christianity and moral torment in a Papua
New Guinea society. Berkeley: University of California Press.

TUZIN, Donald. 1997. The Cassowary's revenge: the life and death of masculinity in a New Guinea society. Chicago: University of Chicago Press.

VIVEIROS DE CASTRO, Eduardo. 1996. "Os pronomes cosmológicos e o perspectivismo ameríndio". Mana. Estudos de Antropologia Social, 2(2):115-144.

WAGNER, Peter. 2005. "Palomar's questions. The axial age hypothesis, european modernity and historical contingency". In: J. P. Arnason, S. N. Eisenstadt e B. Wittrock (orgs.), Axial civilizations and world history. Leiden: Brill. pp. 87-106 


\section{Resumo}

Por que as formas mais populares do cristianismo contemporâneo são aquelas que vêem uma distância radical entre céu e Terra? Com base em teorias acerca do papel da alteridade na religião, e particularmente nas teorias da época axial - que enfatizam a distintividade das religiões afirmadoras de uma relação de alteridade profunda entre o transcendente e o mundano - sugiro que o pentecostalismo se difunde rapidamente devido, em parte, ao modo com que dá destaque a tal alteridade. A globalização, ao tornar tantas pessoas, no mundo, descentradas em suas próprias vidas, produziu um grande reservatório de alteridade mundana vivida como experiência: uma percepção de que os poderes reais deste mundo são diferentes daqueles de cada um, e vêm de outro lugar. Meu argumento é que, para aqueles que experimentam a alteridade nesses termos globais, as religiões axiais, como o pentecostalismo, são boas para pensar, pois reconhecem a distância entre o transcendente e o mundano ao mesmo tempo que sugerem ser possível transpô-la.

Palavras-chave: Pentecostalismo, Paraíso, Globalização, Era Axial, Papua-Nova Guiné

\section{Abstract}

Why are the most popular contemporary forms of Christianity those that envision a radical distance between heaven and earth? Building on theories of the role of alterity in religion, and particularly on axial age theories which emphasize the distinctiveness of religions that posit a profound relationship of alterity between the transcendental and the mundane, I suggest that Pentecostalism is spreading rapidly in part because of the way it highlights such alterity. By rendering so many people in the world 'off-center' in their own lives, globalization has produced a deep pool of experienced earthly alterity, a sense that the real powers in this world are different from one's own and come from elsewhere. Axial religions such as Pentecostalism are, I argue, good to think for those who experience alterity in such global terms because they at once recognize the distance between the transcendental and the mundane and suggest it can be bridged.

Key words: Pentecostalism, Heaven, Globalization, Axial Age, Papua New Guinea 